\title{
A national integrated approach to regulate some specific industrial activities on the basis of the application of Best Available Techniques (BAT) and future perspective under the 2010/75/UE Directive
}

\author{
C. Mazziotti Gomez de Teran, P. Ceci \& A. Fardelli \\ National Research Council, Institute on Atmospheric Pollution, \\ U.O.S. di Roma, Italy
}

\begin{abstract}
Emissions from relevant industrial activities are currently regulated under the 2010/75/UE Directive (IED) on industrial emissions (integrated prevention and control). The purpose of IED Directive is to achieve the integrated pollution prevention and control from large industrial installations. According to the IED Directive, operating conditions required to industrial installations by means of the IPPC permits, shall be based on Best Available Techniques (BAT) in order to reach an adequate level of environmental protection.

The aim of the present paper is to review and pin-point some specific issues associated to the Italian IPPC licensing framework related to the previous IPPC Directive, with the view of the implementation of the IED Directive and the consequent future review and update of IPPC permits released also by taking into account the experience acquired in the recent years.

As a matter of fact, comparability of industrial operating conditions of installations of national relevance and related monitored emissions data is currently a very crucial issue in the process of IPPC licensing, since it is still a challenge the assessment and analysis of similar emission sources, but operating under different conditions that may also be dependent from plant specific characteristics varying from site to site.

Furthermore, the request for improving environmental performance as well as an extensive monitoring of operating conditions at the installation, stimulates the
\end{abstract}


industry, in the long run, to perform their activities more effectively, as described in the present paper.

Thus, in such a legislative framework, monitoring methodologies become more significant not only for deriving information related to the compliance to emission limit values in IPPC permits released, but also for the purpose of the environmental performance assessment of the selected techniques as BAT and for the management procedures associated with the techniques in the industrial installations.

Keywords: 2010/75/UE Directive, IPPC, BAT.

\section{Introduction}

In the context of policies committed to prevent harmful impacts on environment and human health, pollution due to industrial installations has been recognised as a major issue; thus, in the last 20 years an effort has been devoted to promote effective policy instruments, as also recalled in the recent 7 th Environment Action Programme (Decision No 1386/2013/EU [1]). In such a contest it has been developed the Directive 2010/75/UE on industrial emissions (IED [2]). IED Directive has the purpose of achieving integrated pollution prevention and control of pollution arising from large industrial installations. IED Directive covers as much as about 52.000 industrial installations in EU (European Commission [3]) and 5.600 in Italy (National Research Council [4]).

According to such legislation, IPPC permits should be based on Best Available Techniques (BAT) aimed to reach an adequate level of environmental protection and should establish all the necessary measures including operating conditions, emission limit values for relevant polluting substances, monitoring requirements.

The aim of the present paper is to review and pin-point some specific issues associated to the Italian IPPC licensing framework with the view of the implementation of the IED Directive in Italy and the future review of the released permits according to IED for installations of national relevance.

However, in Italy, in spite of difficulties initially encountered in implementing the Integrated Pollution Prevention and Control legislation, nowadays Competent Authorities as well as relevant national stakeholders have been acquired an increased understanding of the whole process and face the implementation of IED Directive in a more structured way, since most of Competent Authorities has gained experience in the IPPC licensing process. Nevertheless, such an opportunity may also allow the enforcement of the dialogue between Competent Authorities at different levels and relevant stakeholders in order to utterly share a common approach.

\section{Background on the IED directive}

IED Directive, entered into force in 2011. It recasts the preceding directives on Integrated Pollution Prevention and Control, i.e. 96/61/EC as amended by Directive 2008/1/EC, into a single legal act with the related legislation on 
industrial emissions, such as Directive 2001/80/EC, on large combustion plants, Directive 2000/76/EC on the incineration of waste, directive $1999 / 13 / \mathrm{EC}$ on the limitation of emissions of volatile organic compounds (VOC), etc.

However, under the IED Directive more than by means of the application of separate single legislative acts, a general improvement on the entire environmental performance of the industrial installations is achieved by taking into account the fate, transport and transformation of pollutants in environmental matrices. Thus, it positively contributes to the protection of the environment as a whole by considering emissions to water, air, soil as well as energy efficiency, waste production, use of raw materials as well as recovering and recycling, prevention of accidents and restoration of the site upon closure.

Moreover, the IED integrated approach requires companies to improve environmental performance. On this purpose, the main instrument to trigger innovation is the provision of implementing Best Available Techniques (BAT), that is the technology used and the way in which the installations is designed, built, maintained, operated and decommissioned, providing an effective level of protection of the environment under economically and technically viable conditions. It is also ensured flexibility or a customization of the application of BAT according to local conditions and the specific characteristic of the installation concerned.

In the exchange of the information process established by art. 13 of IED Directive at the European Integrated Pollution Prevention and Control Bureau (European IPPC Bureau, EIPPCB), the so called "Sevilla Process", comprehensive technical documents on Best Available Techniques REFerence Documents (BRefs) have been developing. BRefs in particular contain relevant information on the emission levels associated with the best state-of-art generally available techniques to be implemented. Under previous IPPC directives, BRefs were used by the competent authorities as a guide with respect to the determination of BAT-based permit conditions at site level. As a matter of a fact, they did not have a legally binding value in order to set emission limit values as well as relevant operating conditions for industrial installations. Moreover, it should be noted that there are BRefs specifically on the relevant industrial sectors, such as large combustion plants, Ferrous Metal Industry, etc. as well as for horizontal issues such as industrial cooling systems and energy efficiency. Revision of BRefs is expected to be carried out every 8 years.

In the IED Directive the BAT concept is strengthened: the BAT Conclusions, that is the chapter of the BRefs that synthetically reports the description, applicability, emission levels associated with BAT (BAT-AELs), monitoring requirements and possibly related measurement methods, associated consumption levels and eventually site remediation measures is approved by means of the art. 75 of Directive 2010/75/UE Committee procedure. Thus, according to IED Directive, BAT Conclusions play a key role in the IPPC licensing process, since Competent Authorities set emission limit values either not exceeding the upper range of BAT-AELs or different emission limit values, periods of time and reference operating conditions so that by means of emission monitoring it is possible verify that emissions under normal operating conditions 
are not exceeding the upper range of BAT-AELs. It is either possible to set a specific derogation in case of proved disproportionately higher costs compared to the environmental benefits, due to the geographical location or the local environmental conditions of the installation concerned or the technical characteristics of the installation. Such derogation are strictly monitored by UE Commission, i.e. no request for derogation could mean a poor level of ambition of the BRef. On the other hand, too many requests would imply that the ambition level of the BRef is too high. Finally, an unjustified concentration of derogation in a specific geographical area could mean the Competent Authority didn't apply the IED correctly.

Thus, in such a legislative framework monitoring methodologies become more significant not only for deriving information related to the compliance to emission limit values set in IPPC permits, but also for the purpose of the environmental performance assessment of the selected techniques as BAT and for the management procedures associated with the techniques in the industrial installations.

Furthermore, it would lead to the harmonization of the monitoring practices. On this purpose the European Committee for Standardization (CEN) and the International Standardization Organization (ISO) has been carrying out a big effort on emission measurement standards at the international level.

IED Directive also contains the requirements on environmental inspections with a site visit every 1 to 3 years, on the base of risk criteria.

Finally, IED Directive also ensures transparency of the decision-making process, also according to the UN/ECE Aarhus Convention on Access to Information, Public Participation in Decision-making and Access to justice in Environmental Matters, signed on 1998, 25th June and entered into force on 2001, 30th October (UN/ECE Aarhus Convention [5]).

\section{Italian experience in IPPC licensing for installations of national relevance}

In Italy the IPPC licensing process foresees a single legal act that covers and replaces the previous sectorial environmental permits required for the installations to operate. For installations of national relevance (Large combustion plants, chemical plants, refineries and iron and steel production) (Decreto Legislativo 3 aprile 2006, n. 152 [6]) the competence for the IPPC licensing is attributed to the Ministry of Environment, while the other installations are licensed by the local Competent Authorities, either Regions or Provinces. Furthermore, installations connected to installations of national relevance or located in the Mediterranean Sea are attributed to the competence of the Ministry of Environment. Thus, in Italy there are currently about 50 Competent Authorities and about 180 installations of national relevance, whose IPPC permits are released by the Ministry of Environment, as well as 5.400 installations, whose IPPC permits are released by the local Competent Authorities (National Research Council [4]) (Fig. 1). 


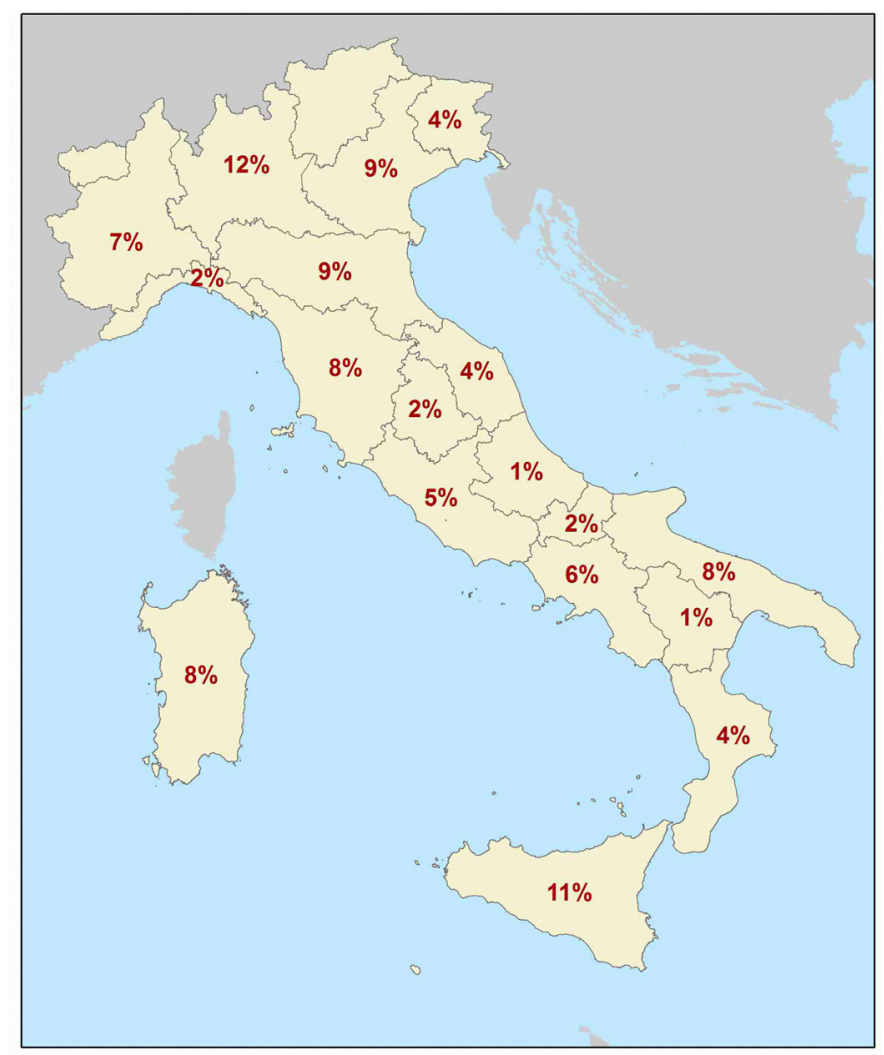

Figure 1: Geographical allocation of installations of national relevance.

The Italian IPPC permits for installations of national relevance are constituted by two main sections: the prescriptive section of the permit is related to the legislative and environmental framework of interest for the industrial installations; its description as it is and as it will eventually become after investments to further improve environmental performances; applied techniques; analysis of BAT applicable to the plant; environmental management system; examination of remarks from the public; prescription related to all the mentioned environmental components, typically water, air, soil, waste production, prevention of accidents and restoration of the site upon closure, maintenance; etc.; actions as well as plans and projects to be developed and carried out while implementing the IPPC licensing (Fig. 2).

The extent of the IPPC permit from 5 up to 8 years depends on the environmental management and quality certificate for the site where the installation is located, or for the industrial activity concerned (Table 1). Such voluntary certification, i.e. UNI EN ISO 14001:2004 or Regulation (EC) No 761/2001 (EMAS), allows companies to eagerly identify and control their environmental impact and constantly improve their environmental performance 


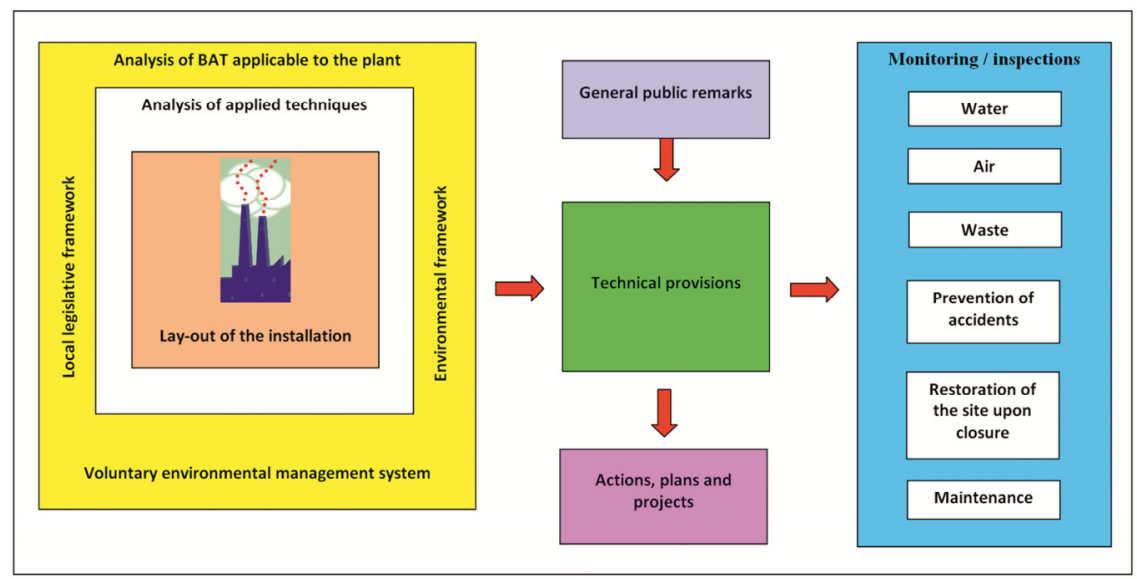

Figure 2: $\quad$ Prescriptive section of the IPPC permit.

Table 1: $\quad$ Extent of the IPPC permit.

\begin{tabular}{|c|c|}
\hline $\begin{array}{c}\text { Extent of the IPPC permit } \\
\text { (years) }\end{array}$ & Voluntary certification \\
\hline 5 & - \\
\hline 6 & UNI EN ISO 14001:2004 \\
\hline 8 & Regulation (EC) No 761/2001 (EMAS) \\
\hline
\end{tabular}

by focusing on specific environmental aspects such as life cycle analysis, communication and auditing.

IPPC permits are also harmonized with requirements coming for ambient air quality plans and programmes according to Directive 2008/50/EC as well as provisions related to safety and prevention of major-accident hazard according to directive 2012/18/UE (SEVESO III).

The prescriptive section is followed by the monitoring and control plan (Fig. 3) which, instead, includes a comprehensive description of the routine monitoring to be performed for each environmental matrix in terms of pollutants, frequencies, etc; monitoring methods according to relevant national and international technical standards (CEN, ISO ad EPA) and related quality assurance and quality control procedures in accordance with EN ISO/IEC 17025:2005; reporting procedures; minimum periodic inspections to be conducted. Thus, monitoring, control and inspection issues are crucial issues in the IPPC permit implementing framework.

Relevant information from monitoring carried out by the operator at the installations or resulting during inspections might be employed by the 
Competent Authorities on the purpose of updating, reviewing the IPPC permits or re-examining environmental performance of the installation after the licensing, as required by the IED Directive.

According to the UN/ECE Aarhus Convention on public information, all Italian IPPC permit as well as relevant information on inspections concerning installations of national relevance are published on the Ministry of Environment web site (Ministry of Environment [7]). Furthermore, in such a data warehouse the majority of the regional IPPC permits are also stored.

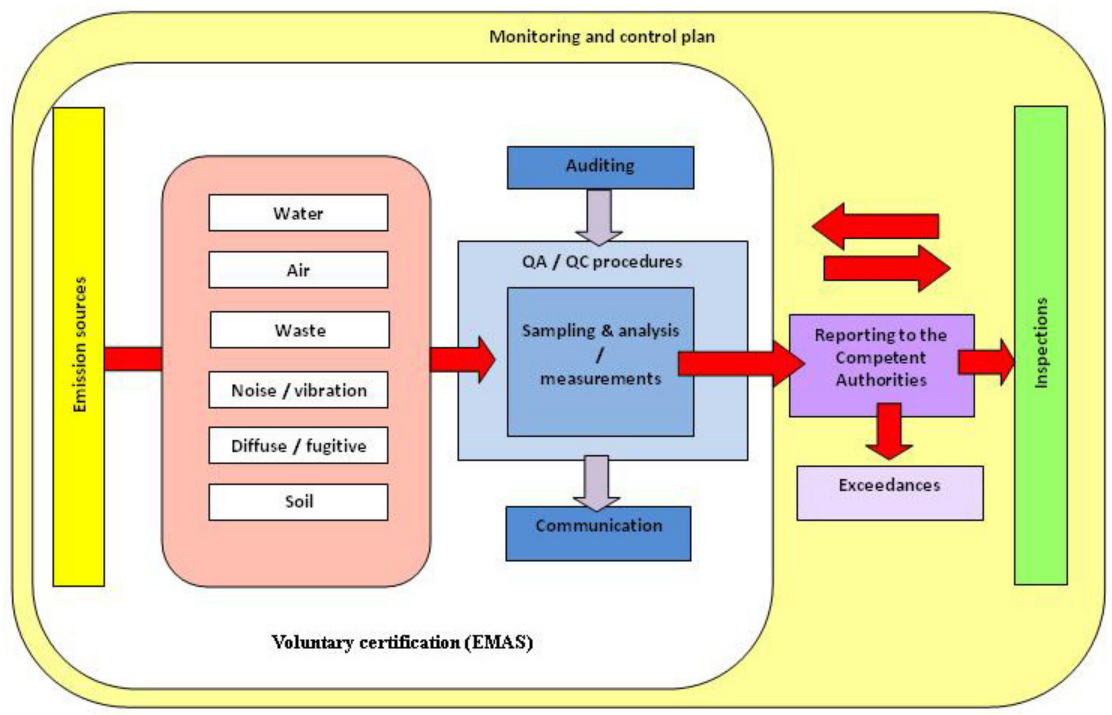

Figure 3: $\quad$ Prescriptive section of the IPPC permit.

\section{The national experience with regard to installations of national relevance}

In Italy many installations are located in Industrial Parks where companies cluster to achieve economic benefits from reduced infrastructure costs and environmental burdens by sharing common synergies, supplying networks, service business, distribution markets, energy efficiency management (Taddeo [10]). In particular, in such areas many complex and well integrated production activities might be present with material cycling and reuse as well as energy recovery, such as petrochemicals, refineries, iron metallurgy industries, shipbuilding and oil seeds working (Fig. 4). Furthermore, besides these, there can be industrial and civil waste waters treatment plants as well as power plants for the production of energy addressing the need of whole area. Thus, through such inter-company partnering this industrial parks can be considered in principle a sort of industrial "metabolism" (Maes et al. [9]), where, which is the conceptually a reaction intermediate or a by-products or a waste of one 
productive activities, might be employed as feedstock in the production process of another installation, allowing material and energy cycling. These exchanges result in cost savings and revenues for the companies, which might be able decrease costs for waste disposal and for secondary raw materials.

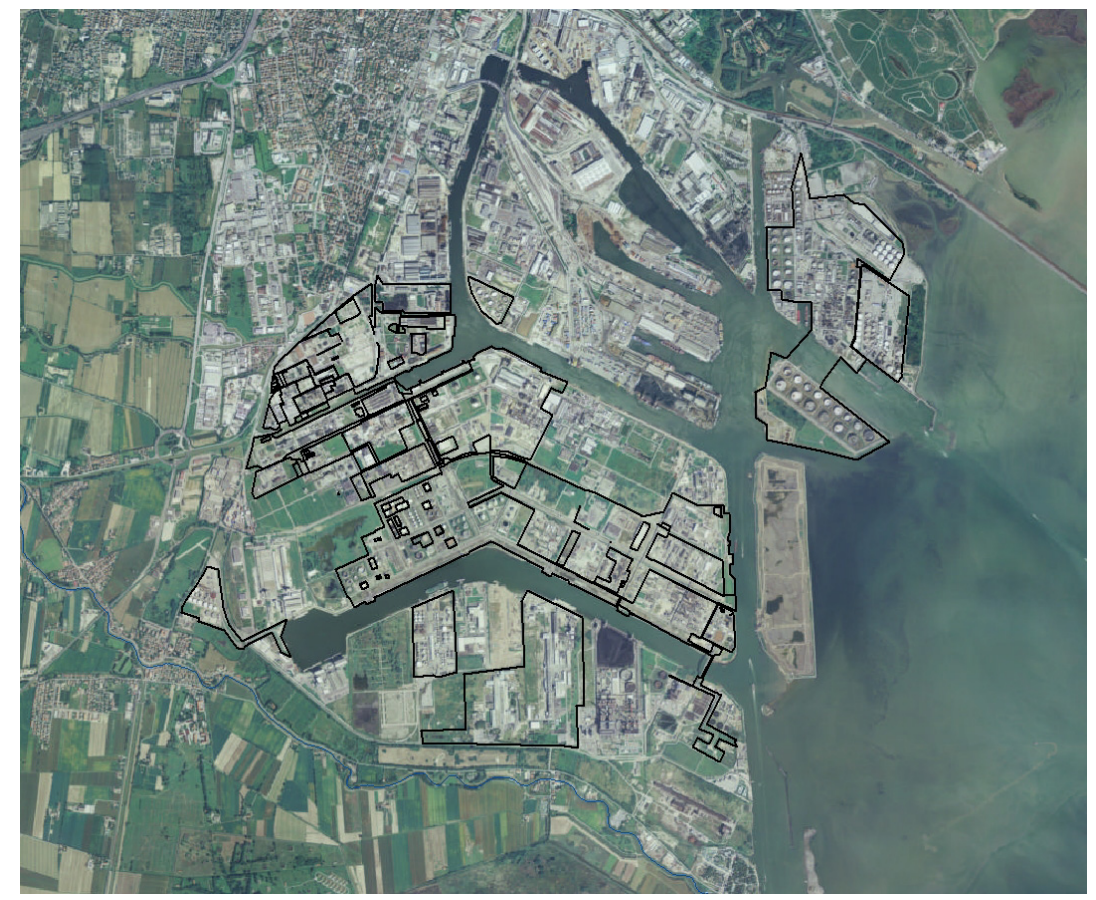

Figure 4: Industrial park of Porto Marghera.

Although since the early 60 s and 70 s such experience of well integrated production activities usually results in a positive practice in Italy, however, it might be that difficulties are faced just by few companies. For example, there are documented cases of installations that encountered a sudden difficulty in finding a fitting for purpose raw material meeting the specific environmental requirements, the plant was designed for, due to the international market changes.

In such a case routine self monitoring data at the installation as established in the monitoring and control plan, clearly showed how the variability of the load composition available for sale, would lead to difficulties in unit management in terms of increased sulphur emissions, lower product yield, increased quantity of by-product, wastes and thermal energy demand, longer operating time with frequent interruption of the interested process unit activities. After further evaluations, the request for updating the IPPC licensed has been submitted in order to revamp partially the interested unit and also to introduce dedicated 
secondary abatement measures at the installation for air pollution control purposes in relation to sulphur (Ministry of Environment [7]).

Hence, not only data acquired for compliance purposes to Emission Limit Values, but also routine self monitoring data are relevant, since it can point out either plant operating conditions to be improved or the need for further reliable and comparable data.

As a matter of fact, according to the monitoring and control plan adequate information in terms of accuracy, completeness, consistency and transparency should be reported to the Competent Authorities on the variations in time of emissions and other parameters that describe the plant operating conditions, such as process physical and chemical parameters, e.g. temperature, pressure, air and water flow, raw material input, production capacity.

The analysis of such information allows the understanding of the trends of certain emissions behaviour by evaluating variations both under normal operating conditions (NOC) and under other than normal operating conditions (OTNOC) (Joint Research Centre [12]). Within the other than normal operating conditions, exceptional emissions are included due to fluctuations in the input or process conditions as well as to start-ups or shut-downs, arrests, malfunctioning and maintenance operations. The exceptional emissions might differ from normal emissions in their volume, composition or concentration. The age of the installation concerned, its specific layout, the variety and extent of the industrial activities should also be considered. In specific cases where emissions during other than normal operating conditions are relevant, a mass flow threshold is usually requested in the IPPC licensing.

Moreover, also diffuse and fugitive emissions, i.e. not emitted into the atmosphere through stacks or ducts, are usually taken into account by means of the request for a periodic maintenance procedure to assess leakages and to remedy, i.e. Leak Detection And Repair program (LDAR).

In Italy flare emissions are also regulated by requesting that under normal operating conditions the emissions are only due to the combustion to the necessary gas to maintain light up the pilot flame and a quantity in terms of mass/time is established on this purpose. The use of flares thus is allowed only for ensuring safety and on emergency purposes. A specific monitoring regime it is foreseen as well as to verify a VOC removal efficiency higher that $98 \%$ at a set minimum temperature in case of usage.

Moreover, in recent years there are documented cases from monitoring analysis at flare that shows that a not negligible quantity of gas used to be combusted. Thus, after further evaluations, the request for updating the IPPC permit released has been submitted in order to modify partially the interested unit and to introduce a gas recovery system.

\section{Conclusions and perspectives}

In this paper we revise some specific issues associated to the Italian IPPC licensing framework related to the previous IPPC Directive with a view to the future implementation of IED directive. 
It would be expected that the transparency of the whole decision-making process would improve the general public awareness on environmental issues increasing the request for further reliable and comparable data.

On this purpose it is worth mentioning that an harmonization of the monitoring practices at UE level has been carrying out within the European Committee for Standardization (CEN) and the International Standardization Organization (ISO), that collaborate with the European Commission to identify suitable measuring methods.

Moreover, an increased comparability of industrial operating conditions of installations is expected to stimulate in the long run the industry to perform their activities more effectively also from an environmental point of view.

\section{References}

[1] Decision No 1386/2013/EU of the European Parliament and of the Council of 20 November 2013 on a General Union Environment Action Programme to 2020 'Living well, within the limits of our planet

[2] Directive 2010/75/UE of the European Parliament and of the Council of 24 November 2010 on industrial emissions (integrated pollution prevention and control) O.J. L 334/17 (2010, 17 December)

[3] European Commission, Proposal for a Directive of the European Parliament and of the Council on industrial emissions (integrated pollution prevention and control) $\operatorname{COM}(2007) 844$ final Brussels, 21 December 2007

[4] National Research Council - Institute of atmospheric pollution - Internal estimate (2014)

[5] UN/ECE Aarhus Convention on Access to Information, Public Participation in Decision-making and Access to justice in Environmental Matters (1998)

[6] Decreto Legislativo 3 aprile 2006, n. 152 "Norme in materia ambientale" G.U. n. 88 (2006, 14 April) as amended by successive acts

[7] Italian Ministry of Environment, Land and Sea web site on IPPC permit releasing ( http://aia.minambiente.it )

[8] Taddeo, R., Simboli, A., Morgante A., Implementing eco-industrial parks in existing clusters. Findings from a historical Italian chemical site Journal of cleaner Production 33, 22-29, 2012

[9] Maes, T., Van Eetvelde, G., De Ras, E., Block, C., Pisman, A., Vehofstede, B., Vandendriessche, F., Vandevelde, L., Energy management on industrial parks in Flanders". Renewable and sustainable Energy Reviews 15 1988-2005, 2011

[10] Joint Research Centre - Institute for Prospective Technological Studies Sustainable Production and Consumption Unit European IPPC Bureau, JRC Reference Report on Monitoring of emissions from IED-installation Final Draft October 2013 (available on the internet: http://eippcb.jrc.ec.europa.eu) 